\title{
AAVV. Homenaje a Miguel Hernández en su centenario. 1910-2010. Prólogo y edición de Maricel Mayor Marsán. Miami: Ediciones Baquiana, Colección “Caminos de la poesía", 2010, 125 pp.
}

Al finalizar la primera de las décadas del siglo XXI, se ha evidenciado que la bibliografía suscitada por Miguel Hernández no sólo es una de las más copiosas que haya generado un escritor hispano moderno y contemporáneo, sino que sigue creciendo de continuo, y desde las distintas vertientes que un poeta ofrece: investigaciones biográficas sobre su vida, así como libros y artículos acerca de su obra. Pero el escritor de Orihuela, además, ha inspirado e inspira a numerosos artistas plásticos, al igual que a creadores de cada uno de los tres grandes ámbitos de la literatura: la novela, el teatro y la poesía.

Ahora bien: siendo él preferentemente un poeta, a nadie puede extrañar que hayan sido sobre todo los poetas quienes figuren al lado de los investigadores a la hora de nutrir ese caudal bibliográfico que, parecidamente al rayo, tampoco cesa. A la altura de 2010, cuando se han cumplido los cien años de su nacimiento, y con motivo de la publicación del volumen Homenaje a Miguel Hernández en su centenario, libro ideado, coordinado, editado y prologado por la escritora Maricel Mayor Marsán, podemos recordar que Miguel Hernández ya inspiró poemas hace más de ochenta años, cuando apenas habían aparecido unos pocos versos suyos en la prensa local. Y es que, en efecto, su amigo de juventud Carlos Fenoll ya compuso en su honor el poema "La sonata pastoril", fechado en Orihuela mismo, el 30 de septiembre de 1929.

En sus versos, Carlos Fenoll se refería a "este pastor ique ha nacido para cantar a su huerta!". Pero no podía imaginarse ese vecino de Miguel Hernández, que tuvo por oficio el de panadero, que ese compañero de aficiones, de fatigas, de contadas alegrías y de numerosas penas, no iba a circunscribir su canto a la huerta oriolana, sino que con el tiempo crearía dos de las obras poéticas más cimeras de la poesía española contemporánea: El rayo que no cesa y Cancionero y romancero de ausencias. Y mucho menos podía sospechar aun que Miguel Hernández sería estudiado, cantado y homenajeado en todos los continentes, pero sobre todo en España y en suelo americano.

Si Carlos Fenoll fue quien se anticipa en cantarle en España, Rafael Alberti sería quien primero le canta en tierras de América cuando, en 1942, y a raíz de la muerte del oriolano en prisión, compuso en su memoria su "Égloga fúnebre a tres voces y un toro para la muerte lenta de un poeta". Desde entonces y hasta el comienzo del tercer milenio, Miguel Hernández ha sido motivo de frecuente e intensa lectura e inspiración en los diversos países americanos, y tanto por parte de los estudiosos de su obra como por la de creadores de las diversas ramas artísticas, y en esa línea de homenajes surgidos en América se inscribe este originalísimo libro conmemorativo que da pie a mi comentario, un libro en el que, bajo la segura y entusiasta guía de 
Maricel Mayor Marsán, y editado en Miami por Ediciones Baquiana, han participado cincuenta creadores residentes en distintas latitudes del variado mapa territorial de los Estados Unidos, y para el que han realizado diversas creaciones plásticas y literarias.

Ilustra la portada de este Homenaje a Miguel Hernández en su centenario una fotografía en color, y en la que contrastan luz y sombra, instantánea muy representativa de la vida y del ambiente doméstico del poeta oriolano. En ella se capta un espacio emblemático del huerto en el que tantas horas pasó y en el que su imaginación perfilaría tantos ensueños literarios y crearía tantos versos. En ese espacio vemos el redil en el que guardaba las cabras que tantas veces pastoreó, pudiéndose ver también un trozo de la montaña que se alza detrás de la casa familiar, hoy convertida en casamuseo de Miguel Hernández. Un formato más reducido tiene la fotografía que ilustra la contraportada del libro, y en la que contrastando de nuevo sombra y claridad, se capta la ventana de la habitación que ocupó el poeta en su casa oriolana.

La obra va precedida de un prólogo de la compiladora para el que ha escogido un título muy sugerente, el de "Miguel Hernández, ruiseñor de desdichas". Y no cabe duda de que esa expresión de "ruiseñor de desdichas", que él se aplicaba a sí mismo, resulta muy adecuada para caracterizar, en síntesis, sus tribulaciones históricas, en las que experimentó penalidades e infortunios sucesivos hasta la desdicha final de su muerte en prisión. Pero tampoco cabe la menor duda de que Miguel Hernández se habría sentido muy gratificado si hubiese podido alcanzar a ver el amplio reconocimiento que generación tras generación concita su figura y la enorme repercusión filológica y artística que propicia su obra literaria, y de la que este libro es una dignísima muestra.

En su prólogo explica Maricel Mayor Marsán cómo, en sus diferentes viajes a España, se acercó varias veces a la región de Levante en la que nació, vivió, escribió y murió Miguel Hernández, y por supuesto visitó la ciudad de Orihuela, y ahí conoció la casa familiar del poeta. Y no cabe duda de que ese conocimiento directo de los ámbitos concretos en los que se inscribe el perfil y el carácter esencial de la obra del autor de El rayo que no cesa no sólo hicieron crecer en ella su interés y admiración hacia el oriolano, sino que han nutrido sus esfuerzos por difundir su figura, su obra y sus mensajes con ocasión de este primer centenario de su nacimiento. $Y$ aquí hay que añadir, y remarcar, que en su compromiso conmemorativo no le ha faltado el estímulo y el aliento de la Fundación Cultural Miguel Hernández a través de sus dos principales impulsores y gestores, Juan José Sánchez Balaguer y Aitor L. Larrabide.

Considero que este libro tiene un precedente en una anterior aportación al hernandismo realizada por Maricel Mayor Marsán. Me estoy refiriendo al estudio de la autora que fue publicado en el volumen colectivo Presente y futuro de Miguel Hernández, título que se puso a las Actas del II Congreso Internacional sobre el poeta celebrado en el año 2003, y que coordinó Aitor L. Larrabide, siendo sus editores Juan José Sánchez Balaguer y Francisco Esteve. En su día, a aquel trabajo le dio Maricel Mayor Marsán la titulación de “Miguel Hernández: más allá de la poesía y el folklor (Presencia e impacto de su obra en los EE.UU)", una titulación indicativa de que este 
trabajo se ocupaba de la repercusión de la obra del poeta en USA, ya por entonces muy notable, pero circunscribiéndola al campo específico de la investigación filológica.

Pese a estar limitado a dicha área, y pese a tratarse de un artículo, y no de un libro, esa contribución de la autora al hernandismo entronca con ese Homenaje a Miguel Hernández en su centenario, pero a la vez que entronca lo hace desde una perspectiva distinta. Se vinculan esas dos aportaciones porque se centran en ilustrar la estela del poeta oriolano en los Estados Unidos, pero el estudio aparecido en 2003 se ceñía al ámbito de la investigación académica, y el de 2010 abarca diversas opciones creativas, pudiendo afirmarse que ambas contribuciones bibliográficas se asocian entre sí, pero al propio tiempo resultan complementarias la una de la otra, a la vez que a ambas las une y las identifica el entusiasmo y el buen hacer y la eficacia de Maricel Mayor Marsán, quien en Miami ha querido y ha sabido unir dos claves representativas de ese espacio de Florida en el que vive y en el que desarrolla principalmente sus actividades intelectuales: el fervor debido a sus raíces hispánicas, y la preocupación por el logro de la eficacia en los objetivos emprendidos, y que está en consonancia con el carácter estadounidense que desde hace tantos años tiene la ocasión de apreciar y de asumir en el día a día.

Decíamos antes que en Homenaje a Miguel Hernández en su centenario participan cincuenta creadores, entre los cuales se cuenta la realizadora del libro, Maricel Mayor Marsan. Cifra redonda, ciertamente, la de ese conjunto de medio centenar de autores reunidos para la conmemoración de una cifra doblemente redonda, la de la centena primera del nacimiento, en Orihuela, del autor homenajeado. Decíamos antes también que todos los que han participado en este tributo residen en diferentes territorios estadounidenses, pero ahora toca precisar que, de ellos, el más representado es Florida, porque los creadores residentes en este Estado suponen la mitad de los participantes en la obra, y siguiéndoles, a notable distancia, los que viven en Nueva York, y a más distancia todavía los que tienen su casa en Texas y Nuevo México. Y no son sólo esos cuatro los Estados que tienen representación en el libro, porque son media docena más, aunque su presencia en él resulta testimonial, si bien no menos interesante y significativa.

Por lo que hace al lugar de origen de quienes han ofrecido su homenaje creativo al poeta levantino, casi la mitad de ellos son cubanos, seguidos muy de lejos por autores nacidos en México, Colombia y Puerto Rico. Podría hacer mención asimismo de la procedencia de los demás componentes de esa nómina de creadores, pero para no extenderme diré que en el elenco de participantes figuran varios nacidos en USA, uno en Brasil, dos en España y uno en Italia. A modo de resumen de cuanto se acaba de señalar, se desprende que el peso más sustancial de este libro pensado y editado en Miami le ha correspondido, sin desdoro de cualesquiera otras participaciones, a la de Florida, y en ella a la nutridísima contribución cubana, una vez más ligada a la memoria de Miguel Hernández.

El poeta oriolano fue un escritor cuyo quehacer se manifestó en varias vertientes, pues no sólo compuso poemas, sino que elaboró piezas teatrales, desarrolló una gran 
actividad periodística y hasta creó textos narrativos en prosa. Pero no cabe duda de que el campo en el que iba a distinguirse fue el de la poesía, y seguramente es por ese motivo que es a los poetas a quienes más ha interesado, interesa e interesará su obra. Es ésa una realidad bien lógica, y el libro Homenaje a Miguel Hernández en su centenario la refleja. Y es que, en efecto, más de dos tercios de la obra son composiciones poéticas, complementándose la misma con muestras de narrativa, de fotografía y de artes plásticas, como el dibujo, y hasta en un caso la escultura, trasladada a las páginas mediante la fotografía.

Son numerosas las creaciones coleccionadas en este libro por Maricel Mayor Marsán que en su título citan expresamente el nombre de Miguel Hernández, o hacen referencia a poemas o a versos suyos, cuando no a su mundo y a sus circunstancias. Sin embargo, con independencia de tales o cuales referencias expresas, lo que se percibe en la obra es que el influjo del poeta de Orihuela, y asimismo el homenaje a su vida y a su literatura, está en todas y en cada una de las contribuciones a este tributo al autor del Cancionero y romancero de ausencias.

Diré también que, aun cuando todas las participaciones de estelibro seencaminan a un mismo fin, el del homenaje, la variedad de tonos y de perspectivas conducentes a él son muy diversas, y no sólo porque Maricel Mayor Marsán ha querido que en esta obra convivan diferentes generaciones, sino porque las estéticas son en muchos casos bien diferentes unas de otras, y lo son desde la clase de corriente desde la que se crean, desde el punto de vista adoptado, desde la modalidad textual elegida, sea elegíaca, sea recreadora, sea memorialística, etc.

Me parece de justicia remarcar, asimismo, la alta calidad de las contribuciones a esta obra, lo que era esperable si atendemos al excelente, rico y vario currículo de quienes han participado en ella. Es cierto que ese currículo es más breve en los casos de personas pertenecientes a las generaciones más jóvenes, pero ya se adivina en ellas que están apuntando a una gran proyección, y que ya hoy merecen figurar al lado de tantas trayectorias desarrolladas, muchas desde la filosofía y la cátedra, y cuya solvencia se ha visto reconocida con puestos profesionales de relieve y con la obtención de premios de carácter internacional.

Al término del poema inicial de El rayo que no cesa, hizo Miguel Hernández un pronóstico nada difícil de aventurar: “...Algún día/ se pondrá el tiempo amarillo/ sobre mi fotografía". Sin embargo, ante la realidad fehaciente de este libro publicado en Miami, no considero demasiado atrevido por mi parte pronosticar que la obra hernandiana, y especialmente su poesía, que ya ha ganado el presente, también tiene trazas de que va a ganar el futuro.

José María Balcells 